Research Article

\title{
Smart and IoT-Based Coupling and Coordination Development for Financial and Logistics Industries
}

\author{
Ji-you Li $\mathbb{D}^{1}{ }^{1}$ Qi-qing Zhou $\mathbb{D}^{1},{ }^{1}$ and Pan-pan Yin $\mathbb{D}^{2}$ \\ ${ }^{1}$ Shaanxi Institute of International Trade \& Commerce, Shaanxi, Xi'an 712046, China \\ ${ }^{2}$ South-Central University for Nationalities, Hubei, Wuhan 430074, China \\ Correspondence should be addressed to Qi-qing Zhou; 2019110135@mail.scuec.edu.cn
}

Received 16 July 2021; Revised 10 August 2021; Accepted 9 September 2021; Published 18 September 2021

Academic Editor: Fazlullah Khan

Copyright $(2021$ Ji-you Li et al. This is an open access article distributed under the Creative Commons Attribution License, which permits unrestricted use, distribution, and reproduction in any medium, provided the original work is properly cited.

Based on the panel data, collected through various Internet of Things (IoT) devices, of 31 various provinces and cities in the Republic of China from 2004 to 2019, due to the analysis of mechanism and the significance of coupled and coordinated development, methods like fuzzy comprehensive evaluation, entropy, coupling, and coordination degree model, exploratory spatial data analysis, and Theil index are widely used to analytically evaluate the dynamic coupling development of China's financial and logistics industries. The analysis of the collected data shows that demand promotion, technological progress, corporate decision-making, and policy stimulus are the driving forces for the coordinated development. In addition, the coordinated development of both industries can achieve a win-win situation. Moreover, during the sample period, the level of coupled and coordinated development has made considerable progress, achieving a transition from moderate to slightly unbalanced level, but overall, it is still at a low level. The level of coupled and coordinated development is showing east-central-west, that is, a three-level declining trend. Guangdong is the province with the highest level, and Qinghai and Ningxia are the provinces with the lowest levels of coupled and coordinated development. The general evolution trend of the total difference in the levels of coupled and coordinated development is declining in fluctuation, and the differences in the eastern region and within the zones are the main reasons for the total difference.

\section{Introduction}

At present, China's financial industry is entering a new normal period. With the increasingly obvious trend of deposit financing and the rapid development of Internet finance services, the ability of financial institutions to obtain low-cost funds in batches continues to weaken. At the same time, financial reform and innovation have entered the deepwater zone, foreign banks have poured in, and private banks have begun to appear. Internet financial services have launched an adverse impact on traditional financial services and offerings. Bank profit margins have significantly narrowed, and off-balance sheet business risks have increased sharply. Under the fierce market race, the competition among commercial banks has turned white-hot, and it has become the Red Sea in the scope of traditional financing business. Therefore, adjusting their own organizational structure, improving their own innovation capabilities, and innovating financial products have become the consensus of the state-of-the-art and modern financial communities in this new era of big data and IoT services.

At the same time, China's logistics industry is entering a new stage of medium-to-high-speed growth of about $10 \%$ after experiencing a high growth stage with an average annual growth rate of approximately 20\% from 1990 to 2000 and an average annual growth rate of approximately 15\% from 2001 to 2010. The current logistics industry has fully entered the Red Sea era, with low price competition among enterprises, higher costs, and lower prices, resulting in price contradictions. Subsequently, this has affected the profit margins of basic logistics businesses such as warehousing and transportation which are declining. Therefore, the logistics industry also urgently needs to find a new profit growth point. 
The theory of industrial integration has pointed out the direction for the development of China's financial and logistics industries. Promoting the coupled and coordinated development of China's financial and logistics industries can effectively solve the difficulties faced by both industries, as discussed above, and can bring win-win results. In this paper, we use the panel data of 31 provinces and cities across China to measure the level of coordinated development of the financial and logistics industries, while previous scholars mostly used time-series data. Following are the main innovations points of the research presented in this paper:

(1) We discuss a dynamic mechanism of the coupling and coordination development of the financial and logistics industries

(2) We discuss the current situation of the coordinated development of China's financial and logistics industries

(3) We use the panel data of 31 provinces and cities across China to measure the level of coordinated development of the financial and logistics industries

(4) An entropy-based model is used to determine the weight of the index system

(5) We use the Theil index studies for the spatiotemporal evolution of the coordinated development level of China's financial and logistics industries

(6) We analyze the differences in the coupling and coordination relationship between China's financial and logistics industries

The structure of the remaining part of this paper is as follows. Section 2 describes the details of the literature review. In Section 3, we discuss the dynamic mechanism of the coupling and coordination development of the financial and logistics industries. Section 4 describes the significance of the coupling and coordination development of the financial and logistics industries, while Section 5 talks over the current situation of the coordinated development of China's financial and logistics industries. Section 6 is about exploratory spatial data analysis, while Section 7 describes a detailed analysis of the differences in the coupling and coordination relationship between China's financial and logistics industries. Finally, Section 8 concludes this paper along with directions for further research and investigation.

\section{Literature Review}

2.1. Theoretically Explore the Significance of the Coordinated Development of the Financial and Logistics Industries. Zhu Hanmin pointed out that financial development can guarantee, support, supervise, and promote the development of the logistics industry with information as the link [1]. Huang, Songdong, and Chunguang believe that the development of the logistics industry needs strong financial support, and the innovation of the financial industry depends on the sustainable development of the logistics industry [2]. Liu Xiaochun and Peng Zhizhong pointed out that the coordinated development of the financial industry and the logistics industry has created a logistics financial business, which can effectively solve the financing problems of small and medium-sized enterprises and add new profit growth points for financial institutions and logistics enterprises [3]. Liu Yetian and Peng Zhizhong found that the coordinated development of both financial and logistics industries has positive effects such as improved service quality of finance and logistics, reduced cost of logistics services, and controlled financial risks [4]. Erik Hofman found that efficient collaboration between financial institutions and logistics companies can reduce capital occupancy and increase corporate profits [5]. Gago studied the commodity transactions in Latin American countries and regions and found that, for a long period of time, the financial industry and logistics companies have been partially integrated, and the relationship between the two parties has also become closer [6].

2.2. Use the Econometric Model to Test Whether There Is a Coordinated Development Relationship between the Financial and Logistics Industries. Li Xinguang and Zhang Yongqi selected the logistics and financial data of Fujian province from 1984 to 2011. The authors used the SVAR model and impulse response analysis to study the coordinated development of logistics and finance. Their investigation suggests that the insurance industry and financial scale are the Granger reasons for the logistics industry. After a short incubation period, the impact of the insurance industry and the scale of finance show a positive impact on the development of the logistics industry and then gradually disappear. The response of the logistics industry to the impact of the financial development scale is far greater than the response to the impact of the insurance industry [7]. Chen Ling used the SVAR model and found that financial breadth has a long-term positive effect on logistics development, and the impact of logistics development on financial breadth and depth is short-term inhibition and long-term promotion [8]. Xia Yunpeng, Yu Yitong, and Lu Le, based on the financial and logistics-related data of the Fujian province, from 1997 to 2016, analyzed and proved that logistics development has a unidirectional promotion effect on financial development [9].

\subsection{Measurement of the Level of Coupled and Coordinated} Development. Zhang Jianjun and Zhao Qilan adopted a dynamic coupling coordination degree model based on entropy weights and found that the coupling coordination degree of China's financial and logistics industries has realized the evolution from noncoordination to coordination. The total amount of logistics, fixed asset investment in the logistics industry, money supply volume, and the added value of the financial industry are key factors that affect the coordinated development of China's financial and logistics industries [10]. Chu Xuejian and Qian Sainan measured the coordinated development level of China's finance and logistics industries based on the method of coupling coordination degree and gray correlation degree. The state changes from an imbalance to a well-coordinated state. The 
railway operating mileage, the number of people employed in the logistics industry, the input-output ratio of the logistics industry, the scale of social financing, and the loan-to-deposit ratio are the key and most important factors for the interaction and links between the financial and logistics industries [11].

In summary, scholars at home and abroad have done much research on the coordinated development of the financial and logistics industries and have achieved fruitful results, laying a solid foundation for the study of this paper. The innovations of this research are mainly reflected in three aspects. The first is to construct a financial subsystem evaluation system from the three dimensions of scale, structure, and efficiency. The financial scale is expressed in terms of stock transaction volume, FIR, and insurance depth, making the financial subsystem and its evaluation more complete. This also makes its measurement structure more reflective of the level of coordinated and coordinated development of China's financial and logistics industries. The second is to use the panel data of 31 provinces and cities across the country to measure the level of coordinated development of the financial and logistics industries, while previous scholars mostly used time-series data. The third is to use the Theil index studies for the spatiotemporal evolution of the coordinated development level of China's financial and logistics industries and provide a perspective to observe the dynamic difference of the coordinated development level of China's financial and logistics industries [12].

\section{The Dynamic Mechanism of the Coupling and Coordination Development of the Financial and Logistics Industries}

3.1. Demand Driven. From the perspective of traditional financing models, the financing risks of small and microenterprises are high because of weak risk-bearing capabilities and lack of collaterals. However, small and microenterprises are an important part of the national economy and there is a huge demand for financial services. Particularly, after the outbreak of the novel coronavirus pneumonia (NCP) epidemic, the living conditions of small and microenterprises have worsened, and the demand for credit resources has become more vigorous. In order to achieve the goal of six stabilities and six guarantees, the long-term lack of financial support for small and microenterprises must be resolved. As a direct product of the coupled development of the financial and logistics industries, supply chain finance follows the principles of self-compensation trade financing, which can effectively control associated risks and solve the financing problems of small and microenterprises. In addition, the needs of small and microenterprises in the industry chain are becoming increasingly diversified. Except financial service needs, they also put forward the need for closer business contacts and providing information services. Driven by this strong demand for small and microenterprises, the supply chain finance business is booming in the Republic of China.

3.2. Improved Skills. Since the beginning of the new century, the rapid development of science and technology has overturned a series of industrial development models. With the continuous development of big data, cloud computing, Internet of Things (IoT), machine learning, and the continuous innovation of the financial technology, data collection is becoming more convenient. Furthermore, information islands are decreasing day by day, realizing fully enclosed realtime monitoring, information available on the entire network, and intelligent risk management and control. The existence of these technologies reduces the cost of risk control, improves the level of risk control, and provides technical support for the development of supply chain in financial services.

3.3. Corporate Decision-Making. At present, China's financial institutions and logistics companies have entered a new normal period, and the traditional business scope is already the Red Sea. Both the financial and the logistics industries urgently need to find a new profit growth point. The theory of industrial integration has pointed out the direction for the development of China's financial and logistics industries. Promoting the coupled and coordinated development of China's financial and logistics industries can effectively solve the difficulties faced by both industries and can bring win-win results. Therefore, under the guidance of maximizing individual interests, financial and logistics companies will actively develop supply chain financial services to achieve the coupled and coordinated development for industrial growth.

3.4. Policy Pulls. The Chinese government has successively promulgated policies such as the "Measures for the Registration of Pledge of Accounts Receivable," "Guiding Opinions on Actively Promoting Supply Chain Innovation and Application," "Notice on Launching Pilot Supply Chain Innovation and Application," and other policies to actively support the development of supply chain in financial services [10]. The deregulation has cleared the way for China to realize business innovation and promote the coupling and coordinated development of the financial and logistics industries [13].

\section{Significance of Coupling and Coordination Development of the Financial and Logistics Industries}

\subsection{Significance of Coordinated Development of Financial and Logistics Industries to the Logistics Industry}

4.1.1. Provide Financial Communication Services. Finance can provide financial support for the upgrading of logistics equipment, expansion of business scale, attraction of talents, purchase of patents, and so on. Therefore, financial support services can help the industries in reducing logistics costs, improving the quality and level of logistics services, and enhancing the competitiveness of logistics enterprises.

4.1.2. Provide Means of Payment. The logistics industry is one of the industries that value efficiency the most. The financial industry can provide the logistics industry with fast, reliable, secure, and convenient payment tools. 
4.1.3. Provide Supply Chain Financial Services, Keep Close Contact with Customers, and Add New Profit Growth Points. Supply chain in finance business is a direct manifestation and concrete product of the coordinated development and cross-coupling of both financial and logistics industries. The development of supply chain in finance business can further strengthen the connection between logistics enterprises and logistics service customers, consolidate cooperative relations, and consolidate the original business. On this basis, logistics enterprises have obtained a new profit growth point by providing financial services for logistics customers through appropriate and personalized value-added service business.

\subsection{Significance of Coordinated Development of Financial and Logistics Industries to the Financial Industry}

4.2.1. Profit Points. By providing supply chain for financial services, the financial institutions can redevelop their original customers and attract new customer groups. Therefore, an increased number of customers could create a new profit point.

4.2.2. Supply Chain in Financial Services. Enrich the risk control methods and technologies of financial institutions, optimize the financial credit structure, and manage financial risks reasonably. By providing supply chain in financial services, the financial institutions can not only accelerate the applications of big data, cloud computing, IoT services, and other high-tech applications but also strengthen the integration of logistics, capital flow, and information flow. Moreover, this can closely integrate financial supervision and business activities and can greatly improve risk control means and technology to optimize the financial credit structure. Therefore, supply chain can help in reducing financial business risks, reducing the rate of bad debts of financial institutions, and improving the quality of services in financial institutions.

4.2.3. Reduce Operating Costs. In the supply chain finance business, one-time credit can be recycled, which greatly reduces labor costs, loan review costs, operating costs, and other related customers' costs. Therefore, supply chain can help in reducing the operating costs of the financial institutions.

4.2.4. Return Finance to the Essence of Serving the Real Economy. At present, China's financial services separating from the real ones (services) are relatively serious. However, supply chain financial services are based on real-world transactions, which can ensure that financial resources will eventually flow to the real economy of the country.

4.2.5. Loans. It is helpful for financial institutions to complete the annual target of SME loans and complete performance appraisal. To effectively support the development of small, medium, and microenterprises, the central bank requires other banks to achieve "two enhancements and two surpasses"; that is, the proportion of the SME loans and the small and microenterprise loans continues to increase. This means that the growth rate of loans is higher than the growth rate of all loans. Promoting the coordinated development of the financial and the logistics industries and actively applying the supply chain for financial business will help financial institutions to achieve their performance evaluation goals.

\section{The Current Situation of Coordinated Development of China's Financial and Logistics Industries}

Referring to the practices of Liu Mingfei and Li Lan [13], Zhang Yi, Chen Qi [14], Chen Ling [8], and other scholars, this paper selects value added of transportation, storage and postal industry, cargo transportation volume, cargo turnover volume, and other indexes from the two dimensions of supply and demand as the measurement indexes of the logistics industry. The financial correlation rate, insurance depth, and financial structure are selected from the three dimensions of scale, efficiency, and structure as the measurement indexes of the financial industry. The financial structure indexes are based on the practice of Liu Guanchun [15]. The index weights of the financial subsystem and the logistics subsystem adopt the entropy method as the value method. Using the entropy method as the weight value method requires six (6) calculation steps (as given in Algorithm 1). Let us consider the logistics subsystem as an example to demonstrate how we can use the entropy method to determine the weight of the index system.

The data sources of the various indicators used in this article are as follows: financial institutions' RMB deposits and loans at the end of the year and GDP data are derived from the statistical yearbooks of various provinces and cities in China, and the stock turnover is derived from the "China Securities and Futures Statistical Yearbook." The population data come from the "China Statistical Yearbook," and the rest of the data are obtained from the data query column of the official website of the National Bureau of Statistics (http://www.stats.gov.cn/). The GDP data is from the statistical yearbooks of various provinces and cities, stock transactions are derived from the "China Securities and Futures Statistical Yearbook," the data on the number of employees in the transportation, warehousing, and postal industries comes from the "China Statistical Yearbook," and the rest of the data is obtained from the data query section of the official website of the National Bureau of Statistics.

After substituting China's financial and logistics-related index data, the evaluation system for the development level of China's financial and logistics industries is obtained as shown in Table 1.

Referring to the research of Zhang Jianjun, Zhao Qilan [10], Chu Xuejian, Qian Sainan [11], and so on, the coupling measurement model of China's financial and logistics industries is given by 
Step 1: standardize the data by linear proportional transformation method (positive index): $X_{i j t}^{*}=x_{i j t} /$ MAX $x_{i j t}$ to eliminate dimensions

Step 2: calculate the proportion of the index value of the $i^{\text {th }}$ evaluation object under the $j^{\text {th }}$ index in year $t: y_{i j t}=X_{i j t}^{*} / \sum_{i=1}^{31} \sum_{t=2004}^{2019} X_{i j t}^{*}$

Step 3: calculate the entropy value of the $j^{\text {th }}$ index: $E_{j}=-1 / \ln (31 \times 16) \sum_{i=1}^{31} \sum_{t=2004}^{2019} y_{i j t} \ln y_{i j t}$

Step 4: calculate the coefficient of difference of the $j^{\text {th }}$ index: $G_{j}=1-E_{j}$

Step 5: calculate the weight of index $j: W_{j}=G_{J} / \sum_{j=1}^{6} G_{J}$

Step 6: calculate the comprehensive development level of a subsystem of the $i^{\text {th }}$ province and city in year $t: L_{i t}=\sum_{j=1}^{6} W_{j} X_{i j t}^{*}$

Algorithm 1: Entropy to determine the weight of the index system.

TAвLE 1: China's financial and logistics industries development level evaluation system.

\begin{tabular}{|c|c|c|c|}
\hline Subsystem & Criterion layer & Index layer & Weight \\
\hline \multirow{6}{*}{ Logistics subsystem } & \multirow{3}{*}{ Logistics demand } & Transportation, warehousing, and postal industry added value & 0.177 \\
\hline & & Cargo volume & 0.155 \\
\hline & & Cargo turnover & 0.252 \\
\hline & \multirow{3}{*}{ Logistics supply } & Transportation, warehousing, and fixed asset investment in the postal industry & 0.197 \\
\hline & & Highway mileage & 0.101 \\
\hline & & Number of employees in transportation, warehousing, and postal industry & 0.117 \\
\hline \multirow{5}{*}{ Financial subsystem } & \multirow{3}{*}{ Financial scale } & Financial correlation rate & 0.061 \\
\hline & & Insurance depth & 0.064 \\
\hline & & Stock turnover/GDP & 0.494 \\
\hline & Financial efficiency & Loan/deposit & 0.020 \\
\hline & Financial structure & Stock turnover/loan & 0.361 \\
\hline
\end{tabular}

$$
C=2 \sqrt[2]{\frac{\mathrm{WF}}{(W+F)^{2}}} .
$$

Among them, $W$ represents the development level of the logistics subsystem, $F$ represents the development level of the financial subsystem, $C$ represents the degree of coupling between the logistics and the financial subsystems, and the value range is between $[0,1]$.

To avoid the extreme situation of false evaluation results when the values of $W$ and $F$ are small at the same time and to consider the growth and evolution levels of the two subsystems, a coupling coordination degree model is constructed, which is given by

$$
T=\alpha W+\beta F, D=\sqrt[2]{C \times T} .
$$

Among them, $T$ represents the comprehensive evaluation index of the financial and logistics subsystems and $\alpha$ and $\beta$ are undetermined coefficients, respectively, with a constant value of 0.5 . Similarly, $D$ represents the degree of coupling and coordination between the financial and the logistics subsystems, and its value range is between $[0,1]$, as described earlier. Table 2 describes the classification standard of coupling coordination degree model used in this paper in terms of degree intervals and classification.

After substituting the data of China's logistics and financial subsystems from 2004 to 2019 into the coupling coordination degree model, we obtained the data as illustrated in Table 3.

5.1. Time-Series Analysis. During the inspection period, the level of coupling and coordination of China's financial and logistics industries has made considerable progress, and the degree of coupling and coordination between both industries has continued to grow, achieving a transition from moderate to a slight imbalance level. However, the level of coordinated development of China's financial and logistics industries is still at a relatively low level. As of 2019, the level of coupling and coordination development of China's financial and logistics industries is still in a state of imbalance, and even Qinghai and Ningxia are still in a state of serious incongruity, which shows that there is much space for improvement in the level of coupling and coordination development of China's financial and logistics industries.

5.2. Spatial Analysis. The level of coupled and coordinated development of China's financial and logistics industries shows a three-tiered declining trend from east to middle and west. The eastern region is generally slight imbalance, but the degree of coupling and coordination in most provinces (municipalities) is at a barely coordinated development level. The central region is also slight imbalance in general, but the degree of coupling and coordination in most provinces is at a slight imbalance level. The western region is generally in a state of low-level maladjustment. The degree of coupling and coordination among provinces (municipalities) is uneven. Sichuan is barely coordinated, while Chongqing, Inner Mongolia, Shaanxi, Yunnan, and other provinces (municipalities) are low-level uncoordinated. Furthermore, Qinghai and Ningxia are severely uncoordinated.

5.3. Supply Chain and Economies. Guangdong province is the highest level of coupling and coordination development of China's financial and logistics industries. Since 2014, Guangdong has been barely coordinated development 
TABLE 2: China's financial and logistics industries coupling coordination degree classification standards.

\begin{tabular}{|c|c|c|c|c|c|}
\hline $\begin{array}{l}\text { Coordination degree } \\
\text { interval }\end{array}$ & $\begin{array}{l}\text { Coordination } \\
\text { classification }\end{array}$ & $\begin{array}{c}\text { Coordination degree } \\
\text { interval }\end{array}$ & $\begin{array}{l}\text { Coordination } \\
\text { classification }\end{array}$ & $\begin{array}{c}\text { Coordination degree } \\
\text { interval }\end{array}$ & $\begin{array}{l}\text { Coordination } \\
\text { classification }\end{array}$ \\
\hline$[0,0.1)$ & $\begin{array}{c}\text { Extremely } \\
\text { uncoordinated }\end{array}$ & {$[0.4,0.5)$} & $\begin{array}{c}\text { Slightly } \\
\text { uncoordinated }\end{array}$ & {$[0.8,0.9)$} & Highly coordinated \\
\hline$[0.1,0.2)$ & $\begin{array}{c}\text { Severe } \\
\text { uncoordinated }\end{array}$ & {$[0.5,0.6)$} & Barely coordinated & {$[0.9,1]$} & $\begin{array}{c}\text { Extremely } \\
\text { coordinated }\end{array}$ \\
\hline$[0.2,0.3)$ & $\begin{array}{c}\text { Moderate } \\
\text { uncoordinated }\end{array}$ & {$[0.6,0.7)$} & $\begin{array}{l}\text { Low-grade } \\
\text { coordinated }\end{array}$ & & \\
\hline$[0.3,0.4)$ & $\begin{array}{c}\text { Low-grade } \\
\text { uncoordinated }\end{array}$ & {$[0.7,0.8)$} & $\begin{array}{c}\text { Moderate } \\
\text { coordinated }\end{array}$ & & \\
\hline
\end{tabular}

TABle 3: Coordination and development level of China's financial and logistics industries.

\begin{tabular}{|c|c|c|c|c|c|c|c|c|c|}
\hline & 2004 & 2008 & 2010 & 2012 & 2014 & 2016 & 2017 & 2018 & 2019 \\
\hline Beijing & 0.303 & 0.405 & 0.418 & 0.426 & 0.490 & 0.513 & 0.513 & 0.482 & 0.495 \\
\hline Tianjin & 0.312 & 0.312 & 0.354 & 0.330 & 0.344 & 0.340 & 0.342 & 0.349 & 0.362 \\
\hline Hebei & 0.301 & 0.372 & 0.405 & 0.409 & 0.452 & 0.486 & 0.517 & 0.496 & 0.501 \\
\hline Liaoning & 0.315 & 0.375 & 0.394 & 0.372 & 0.417 & 0.446 & 0.439 & 0.418 & 0.415 \\
\hline Shanghai & 0.372 & 0.499 & 0.515 & 0.461 & 0.525 & 0.563 & 0.553 & 0.531 & 0.569 \\
\hline Jiangsu & 0.319 & 0.379 & 0.419 & 0.423 & 0.473 & 0.516 & 0.512 & 0.493 & 0.524 \\
\hline Zhejiang & 0.312 & 0.383 & 0.435 & 0.422 & 0.467 & 0.528 & 0.516 & 0.510 & 0.540 \\
\hline Fujian & 0.269 & 0.348 & 0.387 & 0.358 & 0.411 & 0.441 & 0.442 & 0.425 & 0.432 \\
\hline Shandong & 0.322 & 0.401 & 0.434 & 0.429 & 0.448 & 0.497 & 0.508 & 0.509 & 0.529 \\
\hline Guangdong & 0.344 & 0.443 & 0.480 & 0.437 & 0.506 & 0.566 & 0.570 & 0.556 & 0.571 \\
\hline Hainan & 0.189 & 0.235 & 0.267 & 0.282 & 0.322 & 0.337 & 0.317 & 0.319 & 0.314 \\
\hline East & 0.305 & 0.377 & 0.410 & 0.395 & 0.441 & 0.476 & 0.475 & 0.463 & 0.477 \\
\hline Shanxi & 0.305 & 0.371 & 0.389 & 0.387 & 0.413 & 0.436 & 0.428 & 0.419 & 0.430 \\
\hline Jilin & 0.257 & 0.327 & 0.311 & 0.308 & 0.341 & 0.372 & 0.371 & 0.373 & 0.381 \\
\hline Heilongjiang & 0.282 & 0.344 & 0.356 & 0.328 & 0.362 & 0.395 & 0.394 & 0.384 & 0.396 \\
\hline Anhui & 0.281 & 0.375 & 0.398 & 0.416 & 0.472 & 0.495 & 0.501 & 0.479 & 0.484 \\
\hline Jiangxi & 0.265 & 0.328 & 0.357 & 0.337 & 0.369 & 0.407 & 0.406 & 0.395 & 0.407 \\
\hline Henan & 0.302 & 0.368 & 0.404 & 0.407 & 0.425 & 0.476 & 0.480 & 0.476 & 0.483 \\
\hline Hubei & 0.294 & 0.370 & 0.389 & 0.382 & 0.433 & 0.472 & 0.471 & 0.463 & 0.485 \\
\hline Hunan & 0.280 & 0.355 & 0.393 & 0.392 & 0.420 & 0.453 & 0.440 & 0.438 & 0.444 \\
\hline Central & 0.283 & 0.355 & 0.375 & 0.370 & 0.404 & 0.438 & 0.436 & 0.428 & 0.439 \\
\hline Inner Mongolia & 0.270 & 0.337 & 0.361 & 0.391 & 0.404 & 0.416 & 0.442 & 0.427 & 0.427 \\
\hline Guangxi & 0.248 & 0.307 & 0.335 & 0.343 & 0.364 & 0.398 & 0.395 & 0.396 & 0.401 \\
\hline Chongqing & 0.243 & 0.317 & 0.351 & 0.342 & 0.376 & 0.410 & 0.408 & 0.398 & 0.410 \\
\hline Sichuan & 0.291 & 0.388 & 0.416 & 0.416 & 0.467 & 0.514 & 0.505 & 0.492 & 0.507 \\
\hline Guizhou & 0.230 & 0.297 & 0.325 & 0.342 & 0.374 & 0.398 & 0.409 & 0.409 & 0.405 \\
\hline Yunnan & 0.284 & 0.319 & 0.345 & 0.336 & 0.381 & 0.423 & 0.433 & 0.422 & 0.441 \\
\hline Tibet & 0.172 & 0.225 & 0.273 & 0.277 & 0.269 & 0.338 & 0.339 & 0.314 & 0.325 \\
\hline Shaanxi & 0.269 & 0.331 & 0.363 & 0.349 & 0.390 & 0.430 & 0.421 & 0.417 & 0.427 \\
\hline Gansu & 0.248 & 0.309 & 0.317 & 0.324 & 0.363 & 0.396 & 0.411 & 0.390 & 0.394 \\
\hline Qinghai & 0.186 & 0.238 & 0.253 & 0.270 & 0.277 & 0.306 & 0.321 & 0.306 & 0.290 \\
\hline Ningxia & 0.183 & 0.222 & 0.245 & 0.265 & 0.270 & 0.300 & 0.299 & 0.283 & 0.291 \\
\hline Xinjiang & 0.266 & 0.348 & 0.353 & 0.352 & 0.392 & 0.412 & 0.448 & 0.407 & 0.419 \\
\hline West & 0.241 & 0.303 & 0.328 & 0.334 & 0.361 & 0.395 & 0.403 & 0.388 & 0.395 \\
\hline Nationwide & 0.275 & 0.343 & 0.369 & 0.365 & 0.401 & 0.435 & 0.437 & 0.425 & 0.435 \\
\hline
\end{tabular}

Note: due to space limitations, the paper only reports on the level of coordinated development of the financial industry and the logistics industry at the end of the year.

between the financial and the logistics industries for 6 consecutive years, and the degree of coupling and coordination has been increasing year by year. There are several reasons for this situation. Firstly, it comes from the strong support of Guangdong governments at all levels. Governments in Guangdong province have successively issued a series of documents such as the "Development Plan for Modern Logistics Industry in Guangdong Province
(2016-2020)," "Implementation Opinions on Promoting the Development of Supply Chain Finance," and other series documents, which strongly supported the development of supply chain finance and other businesses. Secondly, Guangdong has a developed economy, with a large number of manufacturing centers such as Shekou, Dongguan, and Foshan. In addition, Guangdong's third-party logistics is relatively developed, so there is a huge demand for logistics 
development and a demand for increased logistics valueadded services. At last, Shenzhen is the vanguard of China's reform and opening up. New financial formats such as supply chain finance have developed very early and are showing an increasingly better development trend than the other provinces. As early as 2003, Shenzhen Development Bank began to provide " $1+\mathrm{N}$ " supply chain financial services and issued a supporting management system such as the "Measures for the Management of Indirect Financing Customers for Trade Finance Business." After being acquired by Ping An Insurance (Group) Company of China, Ltd., it launched the " $1+\mathrm{N}$ " supply chain financial service. The "Orange e platform," closely linked to all links in the trade process, provided powerful financing service payments for upstream and downstream customers in the industry chain.

5.4. Poor Natural Conditions. Qinghai, Ningxia, Tibet, Hainan, and Tianjin are the provinces with the lowest level of coordinated development of China's financial and logistics industries; especially, Qinghai and Ningxia provinces are still in a serious state of imbalance. The three provinces of Qinghai, Ningxia, and Tibet have poor natural conditions, poor traffic conditions, large historical debts, a small economic hinterland, lack of industrial support, relatively weak demand, and lagging development of new business formats. Various factors have combined to cause their financial and logistics industries in the lowest level of coupling and coordination development.

5.5. Synchronization Model Analysis. If $\mathrm{W} / \mathrm{F}$ is used to measure the leading or lagging degree of the development of the logistics subsystem relative to the financial subsystem, when the ratio is greater than 1 , it means that the development level of the logistics subsystem is ahead of the development level of the financial subsystem. Otherwise, the development level of the financial subsystem is ahead of the development level of the logistics subsystem. When the ratio is equal to 1 , then it means that the two are developing simultaneously. Table 4 shows that, in 2019, most of China's provinces (municipalities directly under the Central Government) are leading to the development level of the financial subsystem in the development of the logistics subsystem. Only the six provinces of Beijing, Tianjin, Hainan, Tibet, Qinghai, and Ningxia are ahead of the development levels of the financial subsystem.

\section{Exploratory Spatial Data Analysis}

The coupling coordination level of China's financial and logistics industries may have spatial dependence or autocorrelation, so Moran's $I$ is used to measure the spatial autocorrelation of the coupling coordination degree. The value of $I$ is calculated as given by

$$
I=\frac{\sum_{i=1}^{n} \sum_{j=1}^{n} W_{i j}\left(D_{i}-\bar{D}\right)\left(D_{j}-\bar{D}\right)}{S^{2} \sum_{i=1}^{n} \sum_{j=1}^{n} W_{i j}} .
$$

Among them, $W_{i j}$ represents the spatial weight of area (city) $i$ and area (city) $j$, using the $0-1$ distribution principle. The value range of Moran's $I$ is between $[-1,1]$. The greater the absolute value of the coupling coordination value, the closer its spatial relationship.

Table 5 shows that, during the inspection period, Moran's I was positive and showed a downward trend. The $P$ value passed the test in 12 years at a significance level of $10 \%$ and passed the test in 6 years at a significance level of $5 \%$. This illustrates that the level of coupling and coordination of China's financial and logistics industries has a certain degree of spatial dependence or autocorrelation. However, due to the obstacles of various factors, this spatial autocorrelation is at a very low level. In the future, it is necessary to strengthen the orderly flow of financial and logistics resources between various provinces.

\section{Analysis of Differences in Coupling and Coordination Relationship between China's Financial and Logistics Industries}

To further clarify the dynamic differences in the coupling and coordination relationship between China's financial and logistics industries, this paper referred to the practices of Xia Huijun, Zhang Guannan [16], Nie Changfei, Jian Xinhua [17], and so on. We measure the difference with time and space evolution and analyze the reason for it in depth. The specific measurement method is computed using equations (4) and (5), respectively:

$$
\begin{aligned}
& T_{i t}=\frac{1}{n_{i}} \sum_{j=1}^{n} \frac{Q_{j t}}{\bar{Q}_{i t}} \ln \left(\frac{Q_{j t}}{\bar{Q}_{i t}}\right), \\
& T_{t}=T_{W t}+T_{B t}=\sum_{i=1}^{n} \frac{Q_{i t}}{Q_{t}} \ln \left(\frac{Q_{i t} / Q_{t}}{n_{i} / n}\right)+\sum_{i=1}^{n} \frac{Q_{i t}}{Q_{t}} * T_{i t},
\end{aligned}
$$

where $T_{i t}$ represents the region $i$ ( $i=1$ for eastern, $i=2$ for central, and $i=3$ for western) and Theil index in year $t$. Moreover, $Q_{j t}$ is the coordinated development level of the financial and logistics industries of province $j$ in year $t$. Similarly, $n_{i}$ is the number of provinces in region $I$ and $\bar{Q}_{i t}$ is the average level of coordinated development of the financial and logistics industries in region $i$ in year $t$. Furthermore, $T_{t}$ represents the national Theil index in year $t, T_{W t}$ represents the interregional difference in year $t$, and $T_{B t}$ represents the intraregional difference in year $t$. In addition, $Q_{i t}$ is the sum of the coordinated development level of the financial and logistics industries of region $i$ in year $t$, and $Q_{t}$ is the sum of the level of coupling and coordination development of the financial and logistics industries across the country in year $t$. The contribution of intraregional differences to the total difference is $T_{B t} / T_{t}$, the contribution of interregional differences to the total difference is $T_{W t} / T_{t}$, the contribution of intraregional differences to the total difference in the eastern, central, and western regions is as follows: $\left(Q_{1 t} / Q_{t}\right) * T_{1 t} / T_{t}$, $\left(Q_{2 t} / Q_{t}\right) * T_{2 t} / T_{t}$, and $\left(Q_{3 t} / Q_{t}\right) * T_{3 t} / T_{t}$, respectively. 
TABLE 4: Synchronization model analysis result display diagram.

Province

Financial subsystem ahead

Logistics subsystem ahead

Beijing, Tianjin, Hainan, Tibet, Qinghai, and Ningxia Other provinces (municipalities)

TABLE 5: The spatial correlation of coupling and coordination relationship between financial and logistics industries.

\begin{tabular}{|c|c|c|c|c|c|}
\hline Year & $I$ & $E(I)$ & $\mathrm{Sd}(I)$ & $Z$ & $P$ value \\
\hline 2004 & 0.160 & -0.033 & 0.107 & 1.798 & 0.036 \\
\hline 2005 & 0.166 & -0.033 & 0.108 & 1.855 & 0.032 \\
\hline 2006 & 0.140 & -0.033 & 0.107 & 1.629 & 0.052 \\
\hline 2007 & 0.014 & -0.033 & 0.107 & 0.445 & 0.328 \\
\hline 2008 & 0.086 & -0.033 & 0.107 & 1.122 & 0.131 \\
\hline 2009 & 0.094 & -0.033 & 0.107 & 1.198 & 0.116 \\
\hline 2010 & 0.173 & -0.033 & 0.107 & 1.917 & 0.028 \\
\hline 2011 & 0.168 & -0.033 & 0.108 & 1.861 & 0.031 \\
\hline 2012 & 0.168 & -0.033 & 0.109 & 1.84 & 0.033 \\
\hline 2013 & 0.150 & -0.033 & 0.109 & 1.685 & 0.046 \\
\hline 2014 & 0.130 & -0.033 & 0.108 & 1.51 & 0.065 \\
\hline 2015 & 0.119 & -0.033 & 0.108 & 1.415 & 0.079 \\
\hline 2016 & 0.127 & -0.033 & 0.109 & 1.476 & 0.070 \\
\hline 2017 & 0.064 & -0.033 & 0.109 & 0.891 & 0.187 \\
\hline 2018 & 0.120 & -0.033 & 0.109 & 1.408 & 0.080 \\
\hline 2019 & 0.142 & -0.033 & 0.109 & 1.612 & 0.054 \\
\hline
\end{tabular}

TABle 6: The dynamic difference of coupling and coordination development level of China's financial and logistics industries based on the decomposition of Theil index.

\begin{tabular}{lcccccc}
\hline Time & East & Central & West & Total difference & Interregional difference & Intraregional difference \\
\hline 2004 & 1.112 & 1.032 & 0.877 & 0.015 & 0.005 & 0.009 \\
2005 & 1.124 & 1.016 & 0.876 & 0.016 & 0.006 & 0.010 \\
2006 & 1.118 & 1.021 & 0.878 & 0.016 & 0.004 & 0.010 \\
2007 & 1.103 & 1.005 & 0.902 & 0.015 & 0.005 & 0.011 \\
2008 & 1.101 & 1.035 & 0.884 & 0.016 & 0.004 & 0.011 \\
2009 & 1.104 & 1.015 & 0.894 & 0.013 & 0.005 & 0.009 \\
2010 & 1.110 & 1.015 & 0.889 & 0.014 & 0.004 & 0.009 \\
2011 & 1.102 & 1.010 & 0.900 & 0.013 & 0.003 & 0.009 \\
2012 & 1.083 & 1.013 & 0.915 & 0.010 & 0.004 & 0.008 \\
2013 & 1.095 & 1.012 & 0.905 & 0.013 & 0.004 & 0.010 \\
2014 & 1.102 & 1.010 & 0.900 & 0.014 & 0.003 & 0.011 \\
2015 & 1.113 & 1.003 & 0.894 & 0.015 & 0.003 & 0.010 \\
2016 & 1.094 & 1.008 & 0.909 & 0.013 & 0.003 & 0.010 \\
2017 & 1.088 & 0.998 & 0.921 & 0.013 & 0.003 & 0.010 \\
2018 & 1.088 & 1.008 & 0.914 & 0.013 & 0.011 \\
2019 & 1.096 & 1.008 & 0.907 & 0.015 & & 0.00 \\
\hline
\end{tabular}

Through the analysis of the outcomes given in Table 6 and Figure 1, the following conclusions were obtained:

(1) The overall evolution trend of the total difference in the level of coupling and coordination of China's financial and logistics industries shows a downward trend in fluctuations. The total difference between 2008 and before is 0.015 and 0.016 . After 2008, the total difference has declined in fluctuations, and it was 0.013 in most years. This shows that China's measures to promote the coupling and coordination development of the financial and logistics industries have achieved certain results after 2008 that has been improved to a certain extent.

(2) The eastern region is the main reason for the overall difference in the level of coupling and coordination development of China's financial and logistics industries. During the observation period, the eastern region had the largest Theil index and contributed the most to the total difference, followed by the western region, and the central region ranked last. Moreover, the contribution of the eastern region to the total difference is also increasing. 


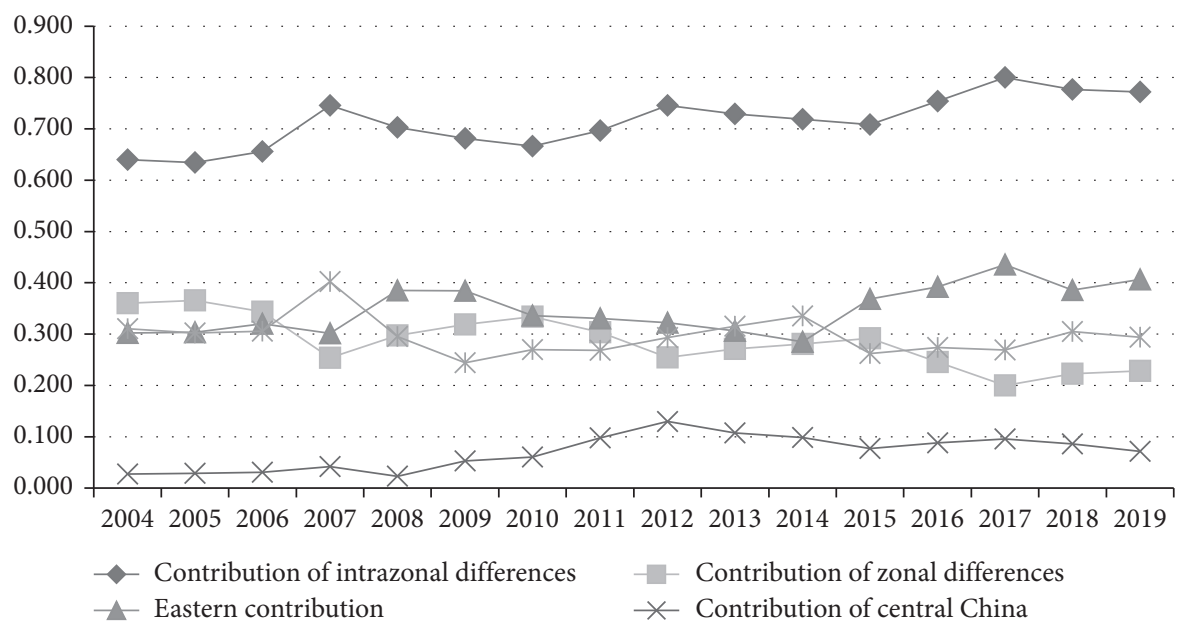

Figure 1: Exploded diagram of the total difference contribution.

(3) Intraregional differences are the main reasons for the overall difference in the level of coupling and coordination development of China's financial and logistics industries. During the observation period, the intraregional difference has been much higher than the interregional difference level, and the contribution of the intraregional difference to the total difference has also been much higher than the contribution of the interregional difference to the total difference. The differences between zones show a trend of convergence, while differences within zones show a trend of expansion. This means that, in future policy formulation, we should focus on differences between regions. Combining the analysis in Section 5, we know that, in the eastern region, Guangdong and other provinces (municipalities) have entered a state of reluctance, but Hainan, Tianjin, and other provinces and cities have a large gap in the degree of coupling and coordination and, therefore, are at a low level of imbalance. In the western region, Sichuan entered a state of bare coordination as early as 2015, but Qinghai and Ningxia are still at a serious level of imbalance. Therefore, the coupling and coordination development of the financial and logistics industries in these provinces and cities needs to be focused on.

\section{Conclusions and Future Research Directions}

8.1. Research Conclusions. According to the comprehensive application of self-compensation trade finance theory, synergy, industry integration theory, financial innovation theory, and other theories, it can be found that demand promotion, technological progress, corporate decisionmaking, and policy stimulus are the driving mechanisms to realize the coupling and coordination development of the financial and the logistics industries. The coupling and coordination development of the two industries can help the financial industry open a new source of profit, enrich risk control methods and technologies, reduce operating costs, complete performance evaluation, and return to the essence of serving the real economy. This also can provide logistics companies with financing services and provision payment methods, close contact with customers, and add new profit growth points. Based on the analysis of fuzzy comprehensive evaluation method, entropy weight method, and coupling and coordination degree model, it can be found that, during the inspection period, the coupling and coordination development level of China's financial and logistics industries has made considerable progress, achieving a transition from moderate to slightly unbalanced change, but in general, still at a low level. The spatial distribution presents a three-tiered declining trend from east to central and west. Exploratory spatial data analysis shows that there is a certain degree of spatial autocorrelation in the level of coupling and coordination between China's financial and logistics industries, but due to the obstacles of various factors, this spatial autocorrelation is at a very low level. The Theil index analysis explains that the overall evolution of the overall difference in the levels of coupling and coordination development of China's financial and logistics industries is a decline in fluctuations. Intraregional differences and the eastern region are the main reasons for the overall difference.

\subsection{Suggestions for Further Improving the Level of Coupling} and Coordination Development of China's Financial and Logistics Industries. The overall improvement strategy for the coupling and coordination development of China's financial and logistics industries strengthens organizational leadership and improves institutional mechanisms and policy systems. Governments at all levels should strengthen top-level design, deepen the reform of "delegating management and service," and optimize the business environment, in terms of taxation, administrative fees, and use, talent attraction, financial services, enterprise mergers and reorganizations, business innovation, and facilitation of government services. From the perspective of the supply chain financial financing model, small and microenterprises are high-quality customer resources for financial institutions. Through the development of supply chain finance business, financial institutions can not only greatly reduce 
financing risks and open new Blue Sea of business but also return to serving the real economy. Small and microenterprises should abandon the idea of a weak position, take the initiative to connect with financial institutions, and actively promote and pilot supply chain financial services.

Furthermore, accelerate the development of financial technology and improve technology-driven efficiency. Fintech provides support for reducing operating costs, enriching risk control methods, and breaking industrial boundaries. It is one of the basic conditions for achieving the coupling and coordination development of the financial and logistics industries. Give full play to the role of market players and comprehensively improve product quality. Enterprise is the microfoundation of economic operation. Financial and logistics companies should combine their own advantages and customer characteristics, increase business innovation, comprehensively improve product quality, and create a batch of competitive supply chain financial products.

Regions with a low level of coupled and coordinated development of the financial logistics industry should learn from regions with a high level of coupled and coordinated development of the financial logistics industry, learn from their excellent practices and development models, and formulate suitable industrial support policies. Through empirical analysis, it can be found that, during the inspection period, the level of coupling and coordination development of China's financial and logistics industries has been greatly improved. Therefore, it is necessary to systematically summarize and sort out the "Guiding Opinions on Actively Promoting Supply Chain Innovation and Application" and other policies, benchmark the eastern region, benchmark Guangdong and other developed provinces, and combine the current economic operating environment to formulate targeted new support policy.

Establish an interprovincial horizontal coordination mechanism. Exploratory spatial data analysis shows that there is a certain degree of spatial autocorrelation in the coupling and coordination level of China's financial and logistics industries, but due to factors such as institutional barriers, this spatial autocorrelation is at a very low level. This is necessary to establish a horizontal coordination mechanism between provinces, strengthen the strategic interaction between the eastern, central, and western provinces, promote the free flow of financial and logistics elements between provinces, and give full play to the high level of coupling and coordination development of financial and logistics industries.

\section{Data Availability}

The data used to support the findings of this study are included within the article.

\section{Conflicts of Interest}

The authors declare that they have no conflicts of interest.

\section{Acknowledgments}

This article is one of the phased research results of the Xi'an Social Science Planning Fund Project "Research on the Relationship between Xi'an Financial Development, Logistics Development and Economic Growth (JX158)." The authors also acknowledge the contribution of the paper "Coupling and Coordination Measurement of the Development Level of China's Financial Industry and Logistics Industry," which was written by the author Qi-qing Zhou, Yu-han Kong, Pan-pan Yin and presented at the 2021 International Conference on Exhibited at Environmental and Engineering Management (EEM 2021).

\section{References}

[1] H. Zhu, "The interactive development of China's financial industry and modern logistics," Journal of Wuhan University of Technology (Social Science Edition), no. 03, pp. 226-230, 2003.

[2] F. Huang, S. Ju, and C. Yi, "Collaborative analysis on modern logistics and finance," in Proceedings of the International Conference on Service Systems \& Service Management, no. 06, pp. 1-5, IEEE, Chengdu, China, June 2007.

[3] X. Liu and Z. Peng, "Application research on coordination development of logistics and finance," China Circulation Economy, no. 04, pp. 23-25, 2009.

[4] H. Liu and Z. Peng, "Research on the construction of the coordination development mechanism of logistics industry and financial industry," Dongyue Review, no. 06, pp. 38-41, 2009.

[5] E. Hofmann and B. Oliver, Supply Chain Finance Solutions, Springer-Verlag, no. 01, , pp. 667-672, Berlin Heidelberg, 2011.

[6] V. Gago, "Financialization of popular life and the extractive operations of capital: a perspective from Argentina," South Atlantic Quarterly, vol. 114, no. 1, pp. 11-28, 2015.

[7] X. Li and Y. Zhang, "Research on the interactive relevance of financial support to the development of logistics industry based on SVAR model-_taking Fujian province as an example," Journal of Shandong University of Technology, no. 04, pp. 15-21, 2013.

[8] L. Chen, "Research on the collaborative development mechanism of regional finance and logistics-_a full-perspective analysis based on the SVAR model," Economic Issues, no. 01, pp. 49-52+57, 2014.

[9] Y. Xia, Y. Yu, and Le Lu, "Applied research on the coordination development of logistics and finance-—an empirical analysis of Fujian province, the core area of the maritime silk road along the belt and road," Logistics Engineering and Management, no. 08, pp. 68-71+76, 2018.

[10] J. Zhang and Q. Zhao, "Research on the coordination development of China's logistics industry and financial industry based on canonical correlation analysis and coupling coordination degree," Industrial Technology Economy, no. 08, pp. 12-19, 2018.

[11] X. Chu and S. Qian, "Research on the coordination development of China's logistics industry and financial industry based on the degree of coupling coordination and the degree of gray correlation," Industrial Technology Economy, no. 07, pp. 93-100, 2019.

[12] A. Ali, Y. Zhu, and M. Zakarya, "A data aggregation based approach to exploit dynamic spatio-temporal correlations for 
citywide crowd flows prediction in fog computing," Multimedia Tools and Applications, pp. 1-33, 2021.

[13] M. Liu and Li Lan, "Analysis of the interaction mechanism between regional logistics and regional economy," Industrial Technology Economy, no. 03, pp. 40-42, 2007.

[14] Yi Zhang and C. Qi, "Research on the coordination of China's regional logistics industry and economic development-_based on the composite system model and panel data of 30 provinces," Soft Science, no. 12, pp. 70-74+79, 2010.

[15] G. Liu, "The financial structure influences the transmission mechanism of the urban-rural income gap_- - a study based on the dual perspectives of economic growth and urbanization," Finance, Trade and Economics, no. 06, pp. 98-114, 2017.

[16] H. Xia and G. Zhang, "Circulation industry development level measurement and spatial visualization distribution dynamic research-— take the Beijing-Tianjin-Hebei urban agglomeration as an example," Business and Economic Research, no. 12, pp. 10-13, 2020.

[17] C. Nie and X. Jian, "Measurement of China's high-quality development and analysis and comparison of inter-provincial status," Quantitative Economics and Technical Economics Research, no. 02, pp. 26-47, 2020. 